\title{
E1 sindicalismo revolucionario en la Semana Roja: la disputa por la dirección de la huelga
}

\author{
Alejandro Belkin \\ UBA - CEHTI \\ ambelkin@gmail.com
}

\begin{abstract}
"El comité [de huelga general] lanzó varios manifiestos, convocó por repetidas veces a los delegados de los gremios, envió circulares al interior llamando a la solidaridad. Fue el centro de relaciones del movimiento huelguista". ${ }^{1}$
\end{abstract}

La institución policial sería tan criminal con Falcón como sin él; ella vive para el crimen y la opresión. ${ }^{2}$

Los sucesos ocurridos en mayo de 1909, conocidos popularmente como "semana roja", constituyeron un hito en la historia del movimiento obrero argentino. Las obras clásicas mencionan su importancia (Abad de Santillán, 1933; Íscaro, 1958; Marotta, 1961; Oddone, 1934), investigadores posteriores también destacaron el valor de aquellos acontecimientos (Bilsky, 1985; Falcón, 1987; Godio, 1972; Suriano, 1988). Sin embargo, a pesar de su formidable envergadura, carecemos de estudios que analicen aquel tramo puntual de la historia del movimiento obrero argentino. El mismo año que ocurrieron los acontecimientos, el Partido Socialista (PS) publicó un informe donde relata su actuación en aquellas jornadas. El documento sobredimensiona la participación del PS en la huelga: "En el origen y desarrollo de los acontecimientos le ha correspondido al Partido Socialista una participación importante, de indiscutible magnitud" (Partido Socialista, 1909, p. 20). Unos años más tarde, profundizando la misma orientación, Enrique Dickmann

1. "Acción del Comité de Huelga General", El Obrero en Madera, II, 31, 1 de junio de 1909 , p. 2.

2. "La renuncia de Falcón: breves consideraciones", La Acción Socialista, IV, 91, 16 de junio de 1909, p. 2.

(Archivos, año V, no 10, marzo de 2017, pp. 13-32) 
elaboró una interpretación global de los sucesos, donde ubica al PS en el centro de la escena y él mismo se sitúa como protagonista central del conflicto (Dickmann, 1949). Esta versión se ha transformado en canónica. En la única obra escrita específicamente sobre el tema, un libro de la Biblioteca Politica de CEAL, los autores quedan prisioneros de esta perspectiva (Frydenberg y Ruffo, 1992). La sobrevaloración del PS, y de la propia figura de Dickmann, llevó necesariamente a minimizar el rol que cumplieron las demás corrientes. El papel que desempeñaron los sindicalistas revolucionarios quedó especialmente relegado. También fue silenciada la disputa permanente que existió entre el Partido Socialista y el Comité de Huelga General (CHG), conformado por anarquistas y sindicalistas, con hegemonía de éstos últimos. Día tras día, durante toda la semana que se extendió la huelga, ambas organizaciones rivalizaron por la dirección del conflicto.

En primer lugar, presentamos la interpretación de los sucesos elaborada por Enrique Dickmann. En segundo lugar, describimos las disputas cotidianas entre el PS y el CHG, rivalidades que contradicen el relato construido por Dickmann. En tercer lugar, desarrollamos los balances que realizaron sindicalistas y socialistas sobre la huelga y sus resultados, analizando las diferentes estrategias politicas que defendía cada fuerza. Por último, subrayamos el protagonismo del sindicalismo revolucionario en estos sucesos. Para efectuar la reconstrucción historiográfica hemos utilizado diferentes fuentes impresas. En primer lugar, hemos examinados en profundidad los periódicos de las tres principales corrientes politicas, La Vanguardia, diario oficial del Partido Socialista, La Protesta, principal vocero del anarquismo, y La Acción Socialista, órgano de difusión del sindicalismo revolucionario. También recurrimos a la prensa gremial: La Unión Obrera, mensuario de la Unión General de Trabajadores y El Obrero en Madera, órgano oficial de la Federación de Trabajadores en Madera. ${ }^{3}$ También incorporamos la visión de la prensa comercial a través del diario La Nación. En este trabajo, circunscribimos nuestra investigación al ámbito de la ciudad de Buenos Aires.

\section{La interpretación apologética de Dickmann}

Para celebrar el $1^{\circ}$ de mayo de 1909 se organizaron dos grandes manifestaciones públicas. Por una parte, la FORA convocó a sus adherentes a concentrarse en la Plaza Lorea, desde allí marcharian hasta la Plaza Mazzini. Los organizadores habian establecido el siguiente recorrido: Callao, Córdoba, Libertad (pasando por el local de La Protesta),

3. El gremio de obreros ebanistas era el principal bastión del sindicalismo en el movimiento obrero. 
Paraguay, Paseo de Julio (actual avenida Leandro N. Alem), hasta el destino. Por otra parte, el Partido Socialista citó a sus simpatizantes en la Plaza Constitución, la manifestación tendría como punto de llegada la Plaza Colón, detrás de la Casa Rosada. La UGT, en cambio, invitó a los trabajadores a una conferencia en el local de Unione e Benevolenza, calle Cangallo 1368 (actual Pte. Perón), organizada por la Federación de Trabajadores en Madera y la Federación Nacional de Obreros Constructores de Rodados. ${ }^{4}$

Cuando la columna de la FORA se predisponía a iniciar su marcha, fue brutalmente reprimida con descargas de máuser. La policía, encabezada por Ramón Falcón, disparó indiscriminadamente sobre la multitud, provocando más de diez muertos y un centenar de heridos. ${ }^{5}$ En sus memorias, Enrique Dickmann realizó una reconstrucción pormenorizada de los acontecimientos (Dickmann, 1949). Su libro constituye un punto de referencia ineludible sobre el tema. ${ }^{6}$ Por ese motivo, presentaremos brevemente sus puntos principales.

El autor comenta que antes de concurrir al mitin del Partido Socialista decidió pasar por Plaza Lorea, "para ver y apreciar la importancia y el espíritu de la manifestación anarquista". Una vez allí, fue "testigo ocular de la terrible tragedia ocurrida". Luego del ataque policial, quedó sobre el pavimento "un tendal de catorce muertos y ochenta heridos, algunos muy graves, que fallecieron a los pocos días". Conmovido por la tragedia, Dickmann dice que comprendió "que había que salvar a la manifestación socialista". Entonces, se dirigió "rápidamente al encuentro del desfile socialista". Alcanzó la cabecera de la manifestación a la altura de Estados Unidos y Buen Orden (Bernardo de Irigoyen). La muchedumbre estaba perturbada por las noticias que llegaban de Plaza Lorea. En ese momento, "alguien lanzó la voz de que la manifestación debía disolverse alli mismo por temor a graves acontecimientos". Según la exposición de Dickmann, "algunos miembros del Comité Ejecutivo, presentes allí, casi aceptaron la indicación". Sin embargo, él se opuso. El dirigente socialista opinaba que "había que conducir, sucediera lo que sucediese, la gran manifestación socialista hasta la plaza Colón". Finalmente, "prevaleció este temperamento". El autor afirma que esa resolución era esperable, porque "el Partido Socialista agrupa en sus

4. "Gran Conferencia", La Unión Obrera, mayo de 1909, p. 4. Emilio Troise y Aquiles Lorenzo pronunciaron sendos discursos, ver "Conferencia del $1^{\circ}$ de Mayo", El Obrero en Madera, 1 de junio de 1909, p. 4.

5. "Detalles de la masacre", La Protesta, 3 de mayo de 1909, p. 1; "El 1 de Mayo, las manifestaciones de ayer, choque sangriento en la avenida", La Nación, 2 de mayo de 1909 , p. 8.

6. Frydenberg y Ruffo (1992) utilizan el texto de Dickmann para relatar los hechos ocurridos. 
filas a lo más inteligente, ordenado, decidido, vigoroso y disciplinado de la clase obrera". Una vez en la Plaza Colón, "veinte mil hombres, ciudadanos y obreros, rodearon la tribuna socialista. Considerables fuerzas policiales, a caballo y a pie, rodearon la plaza". En esa situación extremadamente delicada, Dickmann fue el primero en subir a la tribuna. Estaba convencido de que era necesaria una "acción enérgica contra los autores de tan horrendo crimen". Asegura, tajantemente, que "la duda y la vacilación no son lícitas en el momento de la acción". En su discurso afirmó que Figueroa Alcorta (entonces presidente de la Nación) "ha de estar cansado del movimiento obrero y socialista y ordenó a sus esbirros la represión violenta". Entonces, en ese marco majestuoso, a metros de la Casa Rosada y rodeados por las fuerzas policiales, Dickmann propuso a la multitud "declarar la huelga general y exigir la renuncia del jefe de los asesinos, coronel Falcón”. Los asistentes aclamaron sus palabras, "veinte mil pechos viriles respondieron vigorosa y unánimemente: ¡Viva la huelga general!" (Dickmann, 1949: 158 y ss.).

Una lectura atenta del texto permite identificar los objetivos del autor. Dickmann se propuso reivindicar al Partido Socialista y a su propia figura. Ambos son ubicados como protagonistas de los acontecimientos y ubicados en el centro mismo de la escena. En particular, el autor y el PS aparecen como elementos decisivos en la declaración de la huelga general. Según su relato, Dickmann fue testigo de la masacre, impidió que la movilización socialista se disuelva, impuso su postura en contra de otros miembros del Comité Ejecutivo y finalmente fue él quien proclamó la huelga general y estableció su objetivo político: la renuncia de Falcón. El autor se sitúa como una pieza clave e indispensable de los sucesos. El papel que ocupó el Partido Socialista también se encuentra sobredimensionado. Precisamente, ese fue uno de los debates que tuvieron lugar en aquella época. ¿Quién declaró la huelga general? ¿Quién la dirigió? ¿Cuáles fueron sus objetivos? La respuesta a estas preguntas resultan claves para entender los sucesos y remiten a las disputas por la dirección del movimiento obrero, entre anarquistas, sindicalistas y socialistas. Si fue el Partido Socialista quien declaró la huelga general y paralizó al país, entonces su poder de movilización y su ascendiente sobre el movimiento obrero eran enormes. Además, lo autorizaba a levantar la medida de fuerza. La investigación que hemos realizados nos revela un panorama mucho más mixturado.

\section{La disputa entre el PS y el CHG}

El $1^{\circ}$ de mayo por la noche, en sesión extraordinaria, la Junta Ejecutiva de la UGT dispuso la huelga general a partir del lunes 3 , apegándose a lo resuelto en los últimos congresos de la central obrera. Además, 
resolvió nombrar una comisión para que trate de reunirse con sus pares de la FORA. Por último, decidió citar a los secretarios de las sociedades autónomas para el 2 de mayo para arribar a un acuerdo. Ese mismo día, la FORA también se reunió y acordó convocar a "la Huelga General por tiempo indeterminado para protestar enérgicamente del crimen y como homenaje de respeto a los caídos, que son hermanos nuestros, que son trabajadores". ${ }^{7}$ Por su parte, el PS formalizó su apoyo a la huelga general. "Al terminarse el mitin, el comité ejecutivo del partido socialista celebró una sesión extraordinaria [...] La resolución que adoptó [...] dispone el paro por tiempo indeterminado". ${ }^{8}$ La policía clausuró los centros de reunión del proletariado. Sin embargo, al dia siguiente, en "los locales privados se reunieron por la mañana, y por la tarde y por la noche, los delegados de la mayoría de los gremios". ${ }^{9}$ La emergencia contribuyó a la unidad de las fuerzas obreras. Ese mismo día domingo, se constituyó un Comité de Huelga General (CHG), estaba formado por delegados de la UGT, la FORA y las sociedades autónomas. ${ }^{10}$ Por 1o tanto, los militantes de las organizaciones obreras movilizaron todas sus fuerzas, reunieron a sus gremios clandestinamente, votaron a favor del paro por tiempo indeterminado y crearon un CHG. La convocatoria a huelga general no fue una decisión exclusiva del Partido Socialista, como podría desprenderse del relato construido por Dickmann.

Desde el inicio de la huelga, el Partido Socialista y el CHG se disputaron la dirección del movimiento. El día lunes, primera jornada de huelga, fueron convocadas dos manifestaciones, una organizada por el PS y otra por el CHG. La primera estaba citada en Plaza de Mayo y la segunda frente a la morgue "con el fin de acompañar a su última morada los restos de las víctimas". ${ }^{11}$ "No menos de cuarenta mil personas acudieron a la cita". ${ }^{12}$ Además, el PS y el CHG diferían en las reivindicaciones. El Partido Socialista tenía como principal exigencia la renuncia del jefe de policia, coronel Ramón Falcón. En cambio, las demandas del CHG

7. "F.O.R.A.", La Protesta, 3 de mayo de 1909, p. 1.

8. "El $1^{\circ}$ de Mayo: las manifestaciones de ayer, choque sangriento en la avenida", La Nación, 2 de mayo de 1909, p. 8.

9. "Elocuente despertar del proletariado: la huelga general, triunfo completo de la causa obrera", La Acción Socialista, 16 de mayo de 1909, p. 1.

10. Frydenberg y Ruffo realizan una detallada reconstrucción de los acontecimientos día por día. Sin embargo, saltean la jornada del domingo. Ese día se reunieron los gremios y decidieron su apoyo a la huelga general. Esta llamativa omisión quizás se deba a su apego demasiado pronunciado a la versión de los hechos realizada por el Partido Socialista (Frydenberg y Ruffo, 1992: 48-50).

11. "Ecos del $1^{\circ}$ de mayo", La Nación, 2 de mayo de 1909, p. 6.

12. "El Sepelio", El Obrero en Madera, 1 de junio de 1909, p. 2. 
fueron las siguientes: " $1^{\circ}$ Obtener la libertad de los presos por causas de la huelga; $2^{\circ}$ La reapertura de los locales obreros". Además, en su sesión del lunes, acordó "no dar por terminado el movimiento hasta que no lo resuelva una asamblea que se convocará para ese objeto en los propios locales obreros una vez obtenida su reapertura". ${ }^{13}$ Este último punto era fundamental, porque le quitaba al Partido Socialista la potestad de levantar la huelga general. El diario La Nación expresa con toda claridad esta dicotomía: "La solución del conflicto está, por parte de los socialistas, en la renuncia del jefe de policia, y en cuanto a los ácratas y sindicalistas, en las asambleas gremiales que se realizarian en los locales obreros una vez obtenida su reapertura y la libertad de los trabajadores detenidos". ${ }^{14}$ Esta cita refleja la disparidad de posturas en el campo obrero. Por un lado, los socialistas, por el otro, el bloque compuesto por anarquistas y sindicalistas. Además, deja en claro la división tripartita de las opciones políticas dentro del proletariado.

Una delegación del Partido Socialista, conformada por Alfredo Palacios y Enrique Dickmann, se entrevistó con el ministro del interior, el doctor Marco Avellaneda, en la Casa Rosada (Partido Socialista, 1909: 49). Esta reunión exasperó a las organizaciones obreras, porque entendieron que el PS se arrogaba la representación del movimiento. Además, circuló la versión de que Palacios le ofreció al gobierno "terminar el paro general si se destituye al coronel Falcón". El diario La Protesta salió inmediatamente al cruce de estos trascendidos, aseguró que el "ofrecimiento es por un lado arriesgado y por otro una viveza", porque la declaratoria de huelga general fue realizada por la FORA, la UGT y las sociedades autónomas. Dejando en claro que "no es la huelga la obra de un partido, sino la obra de los trabajadores". ${ }^{15}$

Con anterioridad a los sucesos del $1^{\circ}$ de mayo, la Municipalidad tenía intenciones de aplicar una ordenanza que establecía un nuevo Código de Penalidades "que afectaba la libertad de trabajo de los conductores de vehículos". Además, la disposición incluía "el uso de la Cédula de Vecindad, especie de libreta de conchabo con foto" (Frydenberg y Ruffo, 1992: 67). Los gremios del transporte estaban nucleados en la Federación Gremial de Rodados (FGR), ${ }^{16}$ formada por los Conductores de Carros, Conductores de Vehículos, Protección Chauffers, Empleados de Tranvias, Lecheros, Cocheros Particulares y de Remise. En repudio a la

13. "Acuerdo", La Protesta, 4 de mayo de 1909, p. 1.

14. "La huelga general", La Nación, 4 de mayo de 1909, p. 7.

15. "Mitin socialista", La Protesta, 4 de mayo de 1909, p. 2.

16. "Con representación de siete sociedades de rodados, se dio por reorganizada esta federación, la noche del viernes último [6 de diciembre de 1907]", en "Federación Gremial de Rodados", La Protesta, 10 de diciembre de 1907, p. 2. 
ordenanza municipal, la FGR había declarado la huelga general desde el lunes 3 de mayo. Por ese motivo, el CHG incluyó entre sus demandas la derogación de la ordenanza municipal. Este reclamo se sumaba a los mencionados más arriba, la libertad de los presos y la reapertura de los locales obreros.

El día martes se llevó a cabo un acto multitudinario en la Chacarita, para acompañar el sepelio de los muertos del sábado. ${ }^{17}$ Hablaron varios oradores. Palacios tomó la palabra en nombre del Partido Socialista. El sindicalista Luis Lotito hizo lo propio por las sociedades autónomas. Cerró el acto Juan Bianchi, secretario general de la FORA, en representación del CHG. Al regresar del cementerio, los manifestantes fueron "atacados cobardemente por la policía". ${ }^{18}$ Para el día miércoles 5 también se convocaron dos actos diferenciados. El Partido Socialista citó a sus adherentes en Plaza Constitución a las 16 hs. Por su parte, el CHG, junto con la FGR, resolvieron concentrar sus fuerzas en Plaza de Mayo a las 15 hs. ${ }^{19} \mathrm{El} \mathrm{CHG}$ emitió un comunicado donde afirmaba: "Reunido el Comité Central de huelga, ha resuelto en vista del nuevo e infame atropello llevado a cabo ayer por los sayones policiales, exteriorizar su enérgica protesta llevando a cabo hoy 5 a las 3 p.m. en la Plaza de Mayo un Gran Mitin". ${ }^{20}$ El PS permitió que en su acto hable "el compañero Montesano a nombre de la U.G. de T., F.O.R.A. y Sociedades Autónomas, recriminando los hechos vandálicos de la policía y recomendando la persistencia en la huelga general". ${ }^{21}$ Falcón y la policía impidieron que se realizara el acto en Plaza de Mayo, varios manifestantes que se acercaba al lugar fueron reprimidos y encarcelados. ${ }^{22}$ El día jueves 6, el CHG y el PS también realizaron dos actividades diferenciadas. El CHG dispuso una concentración en Plaza Constitución. En el acto hablaron miembros de las sociedades gremiales, ante numerosos trabajadores. "Tomaron la palabra Montesano y Sibeche, que explicaron las causas de la huelga y la necesidad de proseguir la lucha". ${ }^{23}$ Por su parte, el Partido Socialista convocó a concurrir a la Avenida de Mayo para recolectar firmas exigiendo la renuncia de Falcón. Nuevamente, el quinto día de huelga general, se llevaron a cabo dos manifestaciones distintas

17. El movimiento obrero utilizó en otras oportunidades el ritual del sepelio como acto político y como forma de disputar el espacio público con la autoridad (Lobato, 2011; Suriano, 2001).

18. "A la vuelta del entierro: una nueva masacre", La Protesta, 5 de mayo de 1909, p. 2.

19. "Mitins de hoy", La Vanguardia, 5 de mayo de 1909, p. 1.

20. "Gran Mitin", La Protesta, 5 de mayo de 1909, p. 2.

21. "La huelga general en todo el país", La Protesta, 6 de mayo de 1909, p. 1.

22. "Falconiana", La Protesta, 6 de mayo de 1909, p. 1.

23. "En la Plaza Constitución", La Protesta, 7 de mayo de 1909, p. 2. 
de protesta. El CHG convocó a un mitin en la Plaza Vicente López y Planes, en Montevideo y Las Heras, "frente a la cual tiene su guarida el presidente de la república, con el objeto de producir molestia a ese barrio burgués" ${ }^{24}$ El Partido Socialista realizó un acto en Plaza Constitución. En esta breve reseña de los acontecimientos, quedan en evidencia los desacuerdos entre el Partido Socialista y el Comité de Huelga General. En ningún momento consiguieron conciliar sus posiciones, esas divergencias impidieron que realicen una manifestación callejera unitaria. Cada día que duró el conflicto, el PS y el CHG realizaron actos por separado.

Finalmente, el sábado 8 de mayo el CHG entabló negociaciones con el gobierno. En una reunión gremial efectuada ese día a las 15 hs., se designó una comisión de seis miembros, formada por 2 delegados por la FORA, 2 por la UGT y 2 por las sociedades autónomas. A las 16 hs. dicha comisión se reunió con el presidente del senado, Benito Villanueva, quien concurrió en representación del Poder Ejecutivo, "en cuyo nombre dicho señor propuso las bases de arreglo que constituian las reivindicaciones presentadas por el proletariado en huelga: $1^{\circ}$ Abolición del Código de Penalidades dictado por la Municipalidad; $2^{\circ}$ libertad de todos los presos detenidos por causa de la huelga general; $3^{\circ}$ reapertura de los locales obreros". Ese mismo dia, a las 20 hs., se reunieron delegados de 32 organizaciones y acordaron aconsejar "la vuelta al trabajo en atención a que las reclamaciones presentadas habian sido satisfechas en todas sus partes". Sin embargo, esa "no era una resolución definitiva puesto que iba a ser sometida a la asamblea de los gremios industriales del domingo, en la cual se tomó el acuerdo de reanudar el trabajo". ${ }^{25}$ Además, la FGR realizó un asamblea el domingo 9 a las 14 hs. y también resolvió volver al trabajo. Por lo tanto, también en esta instancia del conflicto, el CHG y los distintos gremios obreros desempeñaron un papel clave. El gobierno accedió a reunirse con una delegación del CHG y se comprometió a conceder todos los reclamos que levantaban las organizaciones sindicales.

El sábado 8 por la noche se reunió el Comité Ejecutivo del Partido Socialista y también decidió "invitar a volver al trabajo a los obreros". Sin embargo, en su declaración no menciona las negociaciones efectuadas por el CHG, ni la asamblea de delegados obreros. La renuncia de Falcón, el objetivo que perseguía el PS, no se había conseguido. Por ese motivo, su decisión de levantar el paro se sustentaba en argumentos diferentes a los sostenidos por el CHG. El PS sostenía que "continuar en la resistencia implicaría para la clase trabajadora hacer más cruentos los sacrificios

24. "Acción del Comité de Huelga General”, El Obrero en Madera, 1 de junio de 1909, p. 2.

25. "Contestando inexactitudes", La Protesta, 15 de mayo de 1909, p. 1. 
y privaciones soportados hasta hoy" y propone "mantener una activa propaganda encaminada a [...] que abandone la jefatura de policía el actual funcionario", ${ }^{26}$ en obvia referencia al coronel Ramón Falcón. ${ }^{27}$

\section{Los balances de la huelga}

La disputa política se tradujo en balances diferenciados. Para los sindicalistas, el desenlace de la huelga fue ampliamente favorable para los trabajadores, "el movimiento fue de tanta magnitud, que tuvo la singular virtud de hacer "capitular" [...] al Poder Ejecutivo". La huelga culminó con un "triunfo completo de la causa obrera", ${ }^{28}$ porque el gobierno concedió todas las reivindicaciones exigidas por el CHG. Los trabajadores "obtuvieron todo cuanto se reclamaba para reanudar el trabajo", y más aún. Porque la "la comisión obrera obtuvo, además, la seguridad, por boca de Villanueva, que no se expulsaría a ningún obrero extranjero". Por lo tanto, se trataba de un "triunfo espléndido, indiscutible". El gobierno fue derrotado completamente, el "poder ejecutivo [...] tuvo que poner en libertad a más de cuatrocientos detenidos por delitos graves; reabrir los locales y dar la seguridad de la derogación del código de penalidades" y también "tuvo que dejar sin efecto su proyecto de aplicación de la ley de residencia".

Para los sindicalistas, constituyó un hecho de trascendental importancia que haya sido el gobierno quien tomó la iniciativa de negociar. El Poder Ejecutivo, "después de ocho días de resistencia tuvo que [...] levantar bandera de parlamento". Más aún, que el poder estatal haya dialogado específicamente con el CHG resultaba todavía más relevante. "El solo hecho de llamar el poder ejecutivo a la comisión de un movimiento de protesta contra las autoridades [...] eso solo constituye un triunfo". Los sindicalistas se mostraron absolutamente deslumbrados porque accedieron a negociar directamente con el gobierno. De acuerdo con su criterio, el hecho marcaba un hito en la historia de las relaciones entre el Estado y el movimiento obrero. "Esto es algo que revoluciona las prácticas seguidas hasta el presente para hacer cambiar la conducta de un gobierno". ${ }^{29}$

El análisis que efectuaron los sindicalistas revolucionarios se forjó

26. "Orden del día del Partido Socialista", La Vanguardia, 9 de mayo de 1909, p. 1. 27. La jefatura de Ramón Falcón (1906-1909) apuntó a una organización más profesional de la policia, reforzando su perfil represivo (Barry, 2010).

28. "Elocuente despertar del proletariado", La Acción Socialista, 16 de mayo de 1909, p. 1.

29. "El Partido Socialista y la huelga general", La Acción Socialista, 1 de junio de 1908 , p. 1. 
en oposición a las posturas del PS. Los socialistas cuestionaron los logros obtenidos. En su prensa aseguraban que resultaba "evidente que, terminada la huelga, se franquearian los locales y se soltarian muchos de los presos. La afirmación de que esas eran las ventajas que perseguía la huelga [...] no se puede tomar en serio". Además, el Código de Penalidades, sostenían los socialistas, había sido "suspendido ya en su aplicación por la autoridad municipal". Asimismo, la huelga se levantó cuando los presos aún permanecian detenidos. Por ese motivo, los socialistas señalaban socarronamente: "esperemos que se cumplan las promesas del gobierno, que no han sido, tampoco cuantiosas". ${ }^{30}$ Los sindicalistas contratacaron afirmando que los socialistas negaban la victoria porque el PS no fue consultado por el gobierno. Recordemos que el CHG estaba compuesto por delegados de la FORA, la UGT y los gremios autónomos. El PS no tuvo ninguna injerencia en la negociación. Además, los sindicalistas tenían mayoría en ese organismo (Frydenberg y Ruffo, 1992: 74), porque contaban con los delegados pertenecientes a la UGT y con los representantes de los gremios autónomos. ${ }^{31} \mathrm{El}$ gobierno conferenció con "una comisión [...] de los que estaban al frente del movimiento", donde el PS no tenía representación alguna. El CHG era el "único capaz de normalizar la situación y volver a dar vida a la industria, al comercio y al transporte". El PS estaba resentido, según los sindicalistas, porque "los doctores del partido no fueron consultados para nada". Por esa razón, los socialistas menospreciaban el triunfo conseguido, "esa es la razón que indujo al órgano socialista a negar la victoria". El Partido Socialista "quiso ponerse al frente del magnífico movimiento", pero fue desoído por los trabajadores, "fue olvidado y todo lo hicieron los delegados obreros, los toscos obreros de manos callosas". $\mathrm{El}$ triunfo de la huelga implicó la derrota del partido. Porque triunfó "el proletariado revolucionario, aquel que combate desde sus organismos sindicales $[\ldots]$ aquel que no acepta la acción legal y parlamentaria [...] aquel proletariado tuvo un triunfo, logró lo que reclamaba". Denunciaban lo que consideraban una impostura del Partido Socialista, "los que siempre se han conformado con migajas y triunfos morales, esta

30. "La reciente huelga general", La Vanguardia, 11 de mayo de 1909, p. 1.

31. Los delegados designados por la UGT fueron José Montesano (ebanista) y Juan Loperena (secretario general de la UGT). En el acto que tiene lugar en la Chacarita el martes 4 de mayo, el sindicalista Luis Lotito tomó la palabra "en nombre de las entidades autónomas". En la asamblea de delegados del sábado 8, se nombró "una comisión para que redacte una extensa declaración dando por terminado el movimiento", se designaron para esa importante tarea a Juan Bianchi (secretario general de la FORA y anarquista), el sindicalista Luis Lotito y Luis Lauzet (sindicalista y secretario de la Federación Gráfica Bonaerense), ver "Elocuente despertar del proletariado", La Acción Socialista, 16 de mayo de 1909, p. 1 y ss. 
vez se muestran más exigentes que los partidarios del todo o nada, tan combatidos por ellos". ${ }^{32}$

Según la opinión de los sindicalistas, la huelga general victoriosa mostró a las claras las potencialidades de la acción directa, el "poder insustituible de la acción directa, se comprueba en el acontecimiento magnífico que ha producido el proletariado de esta región". La huelga general confirmó la eficacia de la acción directa, "destruyendo los falsos conceptos de "lucha" pregonados por los reformistas". La confirmación práctica de la eficacia de la huelga general (entendida como la expresión suprema de la acción directa), demostraba que la lucha parlamentaria (considerada como su opuesto) era completamente inconducente. "Concebir la importancia de la huelga general es destruir toda la ilusión parlamentaria". Los dirigentes del Partido Socialista "saben bien que la acción directa, es la antítesis de la acción parlamentaria, y sostener aquella es quitarle valor a esta". ${ }^{33}$ Sebastián Marotta afirmaba que "la última huelga general ha revelado [...] la superioridad inconfundible del método de acción revolucionaria que caracteriza a la organización sindical: la acción directa". ${ }^{34}$ Por esa razón, los sindicalistas estaban convencidos de que se abrian grandes posibilidades de crecimiento para su corriente, "nunca como ahora los sindicalistas de la argentina hemos tenido la ocasión de alentar nuestras concepciones de la acción obrera". ${ }^{35}$

\section{Cambiar de verdugo}

Hemos visto que el CHG y el PS diferian en los objetivos de la huelga general. La principal consigna defendida por el Partido Socialista consistía en exigir la renuncia de Falcón. El CHG jamás enarboló esa demanda. Los sindicalistas fueron los principales defensores de esta postura. Para justificar esa posición elaboraron una explicación no exenta de complejidades. Sostuvieron que la existencia de la policía es un fenómeno intrínseco de la sociedad burguesa y como toda institución jerárquica necesita de una jefatura. El capitalismo "necesita para su defensa y conservación [...] de una policía, ésta de un jefe". Por lo tanto, un "jefe de policía es la consecuencia del régimen en que vivimos; no es más que un efecto". En otras palabras, no hay capitalismo sin poli-

32. "El Partido Socialista y la huelga general", La Acción Socialista, 1 de junio de 1909, p. 1.

33. "Los triunfos del Partido Socialista...?”, La Acción Socialista, 16 de junio de 1909, p. 2.

34. "Los triunfos del partido Socialista...?", La Acción Socialista, 1 de julio de 1909, p. 2. 35. "Los triunfos del Partido Socialista...?”, La Acción Socialista, 16 de junio de 1909, p. 2. 
cía, y no hay policía sin jefe. A su vez, toda fuerza policial es represiva. Los socialistas, pidiendo la renuncia de Falcón, hacian recaer todas las responsabilidades en un individuo. Transformaban lo que era un problema social en una cuestión de responsabilidad individual. Para los sindicalistas, la "institución policial sería tan criminal con Falcón como sin él; ella vive para el crimen y la opresión". Por lo tanto, el pedido de renuncia del jefe policial, "echa todas las responsabilidades sobre un hombre". En consecuencia, la masacre de la Avenida de Mayo fue producto de la lógica de funcionamiento del sistema capitalista y no se explica por la personalidad irascible de un individuo. Es decir, "de los hechos ocurridos el $1^{\circ}$ de Mayo son culpables [...] todo el mundo burgués, representado en el Estado y sus ramificaciones". Por ese motivo, "seria inoficioso pedir dicha renuncia; más aún, ridícula, tal petición; por eso es que las organizaciones al ir a la huelga general no la han tenido en cuenta". En definitiva, el "estado capitalista vive solamente para la violencia, la que solo desaparecerá cuando lo hayamos derrumbado". En lugar de la renuncia de Falcón, los sindicalistas alentaban su eliminación física, como forma de represalia por las muertes ocasionadas y para infundir temor en los futuros jefes de policía, "lo conveniente y útil sería eliminarlo, para que ello sirviera de ejemplo y tuviese la virtud de morigerar a los que le sucediesen". ${ }^{36}$

El PS, como todo partido opositor, sostenían los sindicalistas, limitaba sus aspiraciones a ocupar puestos en la maquinaria estatal, buscaba reemplazar a quienes ocupan cargos gubernamentales. Pero no se proponía destruir al Estado. Por ese motivo, sus críticas se restringian a determinados individuos, sin analizar los engranajes del cual formaban parte. De esta forma, el Partido Socialista continuaba con "su costumbre de ver a los hombres y no la naturaleza de los puestos que desempeñan". Por ese motivo, "reclamaba la destitución de Falcón". Pero esta exigencia implicaba que sólo "se quería un verdugo nuevo". Es decir, el reclamo por su renuncia, entrañaba un tácito respaldo para su sucesor. "La destitución de Falcón y la vuelta al trabajo con su reemplazo por otro, hubiese sido, quiérase o no, dar el beneplácito al nuevo verdugo". Para los sindicalistas era indistinto quién ocupaba la jefatura de policía. "El proletariado está, estará, descontento contra todo jefe de policía o de estado, llámese con el nombre que se quiera. [...] El proletariado no halla diferencia en que lo asesine Falcón, Fraga, Astorga, o mañana lo asesinen científica y reglamentariamente Palacios o los oficiales socialistas". Por lo tanto, durante la huelga general se desplegaron dos estrategias diferentes. El Partido Socialista "luchaba por su lado para

36. "La renuncia de Falcón: breves consideraciones", La Acción Socialista, 16 de junio de 1909, p. 2. 
obtener otro verdugo, mientras la organización [los sindicatos] lo hacía por el suyo, para protestar contra el asesinato y lograr la libertad de los presos, la reapertura de los locales y la derogación de la nueva ordenanza municipal". Es decir, las organizaciones obreras buscaban modificar "condiciones de hechos y de derechos, sin preocuparse del cambio de personas". ${ }^{37}$

\section{El Partido Socialista y la huelga general}

La posición del Partido Socialista en favor de la huelga general causó perplejidad entre los contemporáneos. El diario La Nación destacó este hecho como una rareza: "Pocas veces el partido socialista ha votado una huelga general. La resolución que adoptó ayer reviste, pues, importancia, pues por ella se dispone el paro por tiempo indeterminado [...] exigiendo la renuncia del coronel Falcón". ${ }^{38}$ Sólo dos días después, el mismo diario reiteró su manifestación de asombro: "merece señalarse la resolución del partido socialista al invitar a los obreros a la huelga general, pues esta medida la adoptó únicamente en una ocasión anterior". ${ }^{39}$ Los sindicalistas criticaron en reiteradas oportunidades a los socialistas por su oposición sistemática a la huelga general. En este caso, tuvieron que explicar las razones que motivaron al PS a inclinarse en favor del paro nacional. Desde su punto de vista, la composición predominantemente obrera del acto del PS obligó a sus dirigentes a declarar la huelga general. La "manifestación socialista [...] estaba constituida en su enorme mayoría de proletarios". La masacre de sus compañeros causó una enorme indignación entre los trabajadores. Los cuadros de conducción del PS eran contrarios a la huelga general pero "llevados por una masa proletaria, se vieron obligados a proclamarla". La ferocidad de la represión policial y el impacto que causó entre los manifestantes, quitó todo margen de maniobra a la dirección del partido. De lo contrario, "si los doctores del partido socialista hubiesen tenido tiempo de meditar y apagar o desviar la impresión producida, consecuentes con sus teorías, se hubiesen limitado a una declaración de condenación de la masacre". Pero "ellos no tuvieron tiempo de meditar" y tomaron una decisión que "desdice varios años de propaganda y desmiente sus propios argumentos sostenidos en congresos, en la prensa y en todos lados". Según los sindicalistas, el apoyo del PS a la huelga general representaba una

37. "El Partido Socialista y la huelga general", La Acción Socialista, 1 de junio de 1908, p. 1.

38. "El $1^{\circ}$ de Mayo: las manifestaciones de ayer, choque sangriento en la avenida", La Nación, 2 de mayo de 1909, p. 8.

39. "La huelga general", 4 de mayo de 1909, p. 7. 
"derrota teórica". Sin embargo, podrian haber obtenido un "beneficio práctico", si hubiesen conseguido coaligar sus fuerzas con las organizaciones gremiales. Es decir, si el CHG y el PS se hubiesen fundido en un único organismo. Esa coalición le "hubiera dado al partido un prestigio inmenso, era el acuerdo que esperaban de la organización sindical y el partido". Sin embargo, esa arreglo "no se produjo", afirmaban complacidos los sindicalistas. No hubo acuerdo organizativo. Sin embargo, se podría haber arribado a un "acuerdo tácito", si el PS hubiese formulado las mismas reivindicaciones que los gremios, "si las peticiones del partido las hubiesen formulado inspirados en las de las organizaciones". ${ }^{40}$ Pero tal cosa tampoco sucedió. Como hemos visto, las reivindicaciones del PS y del CHG diferian. En este análisis, se trasluce la disputa por la conducción del movimiento de protesta, y en términos más amplios, del movimiento obrero.

Todas las fuerzas obreras, FORA, UGT, sindicatos autónomos y Partido Socialista, coincidieron en un único punto, en la declaración de huelga general por tiempo indeterminado a partir del lunes 3 de mayo. Dentro del campo proletario se desplegó una sorda pelea por la conducción y la orientación del movimiento. Desde el inicio mismo de la huelga general, los sindicalistas vieron en el Partido Socialista a un competidor, una organización que trataba de hegemonizar la dirección de la protesta obrera. Por ese motivo, organizaron, promovieron y controlaron el CHG, como organismo opuesto al PS. Pero además, buscaron diferenciar los reclamos de ambos. El tercer dia de paro, el CHG comunicó que "ha prescindido en absoluto del Partido Socialista". Tal decisión no se debía "solamente por no estar de acuerdo con el pedido de renuncia del jefe de policía", sino también "por considerar que el partido no tienen ninguna injerencia en las organizaciones obreras ni puede tenerla". El desacuerdo sobre la renuncia de Falcón era importante, pero lo era aún más la necesidad de diferenciarse del Partido Socialista. Los sindicalistas reconocieron que la mayoría de los trabajadores eran partidarios de exigir la renuncia del jefe de policía. Después de ocurrida la masacre en Avenida de Mayo, "el público todo" sostenía que "debemos pedir su renuncia". ${ }^{41}$ Sin embargo, los sindicalistas presionaron para que el CHG no levante esa consigna. Cuando se constituyó ese organismo, algunos delegados obreros estaban de acuerdo en exigir la renuncia de Falcón. Sin embargo, "tras una breve

40. "El Partido Socialista y la huelga general", La Acción Socialista, 1 de junio de 1908, p. 1.

41. "La renuncia de Falcón: breves consideraciones", La Acción Socialista, 16 de junio de 1909, p. 2. 
discusión, desistieron de tal propósito". ${ }^{42}$ Las organizaciones gremiales actuaron de manera unitaria, conducidas por el $\mathrm{CHG}$, organismo que estuvo hegemonizado por los sindicalistas: el pliego de reivindicaciones lleva su impronta, diferenciado del Partido Socialista. Los sindicalistas trataron de bloquear sistemáticamente cualquier posibilidad de penetración del PS en el movimiento obrero. De esa forma fueron construyendo su propio poder, postulándose como alternativa al reformismo electoralista del PS.

\section{El protagonismo de los militantes sindicalistas y su alianza con el anarquismo}

Los militantes sindicalistas cumplieron un rol descollante en la Semana Roja. Luis Bernard fue testigo de la masacre en Plaza Lorea y luego habló en el acto del Partido Socialista en la Plaza Colón. ${ }^{43}$ "También hizo uso de la palabra nuestro camarada Luis Bernard (testigo ocular de la masacre), exhortando con palabra vibrante a los trabajadores a disponer sus energías y armarse de coraje para contestar a las brutales agresiones policiales". ${ }^{44} \mathrm{El}$ martes 5 de mayo, el Partido Socialista organizó un acto en Plaza Constitución, el sindicalista José Montesano pronunció un discurso a la concurrencia "a nombre del comité central de la huelga", ${ }^{45}$ donde dijo: "Debemos exigir la apertura de los locales obreros y la libertad de los camaradas detenidos". ${ }^{46}$

Ya hemos mencionado que el CHG estuvo hegemonizado por los sindicalistas, estableciendo la estrategia y las metas del movimiento. Cuando el CHG se entrevistó con Benito Villanueva, éste les pidió una dirección postal para enviarles por escrito la contestación sobre la libertad de los presos. Los delegados obreros acordaron en dejar el domicilio de Juan Cuomo, "al pedirse un domicilio para contestar respecto a la lista de los presos, todos convinieron en que lo hiciera al domicilio y nombre de Juan

42. "A propósito de la solución de la huelga general: falsedades reformistas", La Acción Socialista, 16 de junio de 1909, p. 3.

43. "Habló también D. Luis Bernard que dijo haberse encontrado en el lugar de los sucesos y narró diversos detalles que presenció, atacando el proceder de la autoridad", en "El $1^{\circ}$ de Mayo: las manifestaciones de ayer, choque sangriento en la avenida", La Nación, 2 de mayo de 1909, p. 8.

44. "Elocuente despertar del proletariado: la huelga general, triunfo completo de la causa obrera", La Acción Socialista, 16 de mayo de 1909, p. 1.

45. "La huelga general: marcha del movimiento, el mitin socialista", La Nación, 6 de mayo de 1909, p. 10.

46. "En la plaza Constitución: grandiosa asamblea", La Vanguardia, 6 de mayo de 1909 , p. 1. 
Cuomo". ${ }^{47}$ Por ese motivo, la carta que envía el presidente del Senado está dirigida a este militante sindicalista, razón por la cual adquiere gran notoriedad..$^{48}$ En la trascendental asamblea de delegados obreros, realizada el sábado 8 de mayo, Luis Lotito, delegado del gremio gráfico, presentó la moción que fue aprobada por unanimidad y que proponía dar por terminado el movimiento. Para redactar un documento, explicando detalladamente los motivos de aquella resolución, se designó una comisión compuesta por Luis Lotito, Luis Lauzet y Juan Bianchi (los dos primeros sindicalistas, el último anarquista).

El día domingo 9, se realizó la reunión decisiva, en el local de Méjico 2070, donde se decidió reanudar el trabajo. En esa asamblea se presentaron sólo dos mociones, las mismas fueron aprobadas por mayoria de votos, ambas fueron elaboradas por militantes sindicalistas (la primera fue presentada por los ebanistas y la segunda por Ernesto Piot). ${ }^{49}$ Por lo tanto, en el transcurso de todo el movimiento y especialmente en sus momentos decisivos, los sindicalistas ocuparon un lugar de primer orden. La Semana Roja no se puede comprender sin la destacada participación de los militantes sindicalistas.

El análisis de los acontecimientos nos revela la unidad sin fisuras que se forjó entre anarquistas y sindicalistas. No se registraron críticas cruzadas entre ambas corrientes. La FORA y la UGT, anarquistas y sindicalistas, actuaron como un bloque homogéneo. Más aún, se produjo un incidente aislado, cuya resolución muestra la unidad de criterios que prevaleció en esa coyuntura. Una vez terminada la huelga, el 13 de mayo, aparece publicado en las páginas de La Protesta un artículo firmado por un tal Manuel Magdaleno. En el mismo se criticaba la actuación del CHG, el autor reprochaba "la poca y mala acción desplegada por ese comité durante el movimiento". Pero la condena era más amplia, el articulista expresaba su disconformidad con el maridaje establecido entre la FORA y la UGT. El autor afirmaban: "Estoy disconforme, y doy mi opinión [...] para que desaparezca de una vez por todas este concubinato que por tercera vez se repite entre el consejo de la federación y la unión". ${ }^{50}$ Dos días más tarde, en la edición del 15 de mayo, el diario anarquista La Protesta cede sus páginas al dirigente sindicalista Luis Lauzet, para que levante los cargos formulados contra el CHG. La buena

47. "Contestando inexactitudes", La Protesta, 15 de mayo de 1909, p. 2.

48. El contenido de la carta puede leerse en "La huelga general: terminación del movimiento", La Nación, 9 de mayo de 1909.

49. "La reunión de anoche: resoluciones adoptadas por los representantes gremiales", La Vanguardia, 11 de mayo de 1909, p. 1.

50. "Asamblea de delegados: breves consideraciones", La Protesta, 13 de mayo de 1909, p. 1. 
relación entre ambas corrientes resulta evidente. En su respuesta, Lauzet defiende el proceder del CHG durante el movimiento, respondiendo una por una las críticas formuladas por Magdaleno. Lo que resulta más llamativo es la nota de la redacción que se publica a continuación del artículo. En la misma se dice: "Pedimos a los que tengan empeño en seguir ventilando este asunto, lo hagan verbalmente. En el diario es ya suficiente lo que se ha escrito sobre el particular, máxime tratándose de hechos consumados, que pueden estudiarse, pero contra los que ya no se puede volver".$^{51}$ Es decir, la redacción de La Protesta cerró filas con la dirección de la FORA, la UGT y los sindicalistas. El diario ácrata puso fin al debate y clausuró definitivamente toda posibilidad de cuestionamiento por escrito. De esta forma, desactivó toda confrontación con la UGT y los sindicalistas. El blanco de sus criticas fueron los socialistas, en este punto también coinciden con los sindicalistas. Señalaron que el PS, arrastrado por la presión de los acontecimientos, contradijo sus posturas tradicionales al apoyar la huelga general. "Fueron en contra de su táctica, empujados por la fuerza de las circunstancias". Pero la cuestión que más los irritaba, al igual que los sindicalistas, era que el Partido Socialista quería apropiarse de la huelga general. "Ellos declararon que el movimiento fue obra del P.S.A., para demostrar que disponen de fuerzas... ¡Descarados! ¿Hasta dónde llega vuestra impudicia?”. Desde su perspectiva, los acontecimientos habian sucedido de una manera muy distinta, "las sociedades obreras decretaron la huelga general, a la que se adhirieron los socialistas". ${ }^{52}$ Los análisis del periódico libertario confirman que durante la huelga general se desarrolló un forcejeo permanente, apenas disimulado, por la dirección del movimiento. Esta disputa continuó en los balances posteriores.

\section{Palabras finales}

La interpretación que elaboró Enrique Dickmann, donde el PS y él mismo eran presentados como los demiurgos del conflicto, se ha demostrado inexacta. La decisión de convocar a la huelga general fue compartida entre el PS y el CHG, donde los sindicalistas tenían una participación mayoritaria. Las medidas diarias de protestas fueron sostenidas también por ambas organizaciones, disputando palmo a palmo la dirección del movimiento. Estos elementos indican la fuerza que había adquirido el sindicalismo revolucionario y su convicción inalterable de luchar denodadamente por conquistar la conducción del movimiento obrero.

51. "Contestando inexactitudes", La Protesta, 15 de mayo de 1909, p. 1.

52. "Hablemos claro", La Protesta, 13 de mayo de 1909, p. 1. 
La investigación que hemos realizado aporta a la comprensión del vínculo entre los sindicalistas revolucionarios y el Estado. Según Maricel Bertolo, en estos años la corriente atraviesa la segunda fase de su evolución, la cual estaría caracterizada por "una estrategia más abiertamente antiestatista, con claras intenciones insurreccionales [...] una de las consignas que más los caracteriza en estos años, será la de no tratar con las instituciones del Estado" (Bertolo, 1993: 46-47). A la luz de los acontecimientos que hemos relatado, creemos que estas afirmaciones habria que matizarlas. Repasemos los hechos que desembocaron en la finalización del movimiento. En primer lugar, los sindicalistas avalaron, protagonizaron y fueron artífices clave de las negociaciones con el Estado. Sus militantes participaron activamente de los acuerdos con Benito Villanueva, delegado del Poder Ejecutivo. Recordemos que se mostraron deslumbrados por acceder a una negociación directa con el gobierno. En segundo lugar, como ya hemos visto, una de las principales exigencias del CHG era la liberación de los presos. Sin embargo, cuando la huelga se levantó los presos aún continuaban detenidos. Según sus propias palabras "solo faltaba la libertad de los presos; el Código de Penalidades fue abolido de hecho, los locales ya estaban abiertos" ${ }^{53}$ Es decir, los sindicalistas recomendaron la finalización de la huelga amparados en una promesa oficial. ${ }^{54}$ Esta confianza tácita en las palabras de un representante del gobierno despertó resquemores y debates entre la militancia gremial. Sin embargo, los sindicalistas siguieron adelante y avalaron la finalización del paro. Ciertamente, en los días posteriores, más de cuatrocientos presos recobraron su libertad. Empero, algunos obtuvieron su excarcelación bajo fianza. Los sindicalistas consintieron este procedimiento por la delicada situación procesal en la que se encontraban, varios "estaban acusados por disparo de armas". ${ }^{55}$ En el mismo sentido, los delegados sindicalistas comentaron que Villanueva se comprometió, en nombre del gobierno, a no aplicar la Ley de Residencia. En el balance del conflicto, incluian esta promesa gubernamental como parte del triunfo de los huelguistas. En definitiva, los sindicalistas desplegaron todas sus energías en favor de la huelga

53. "Elocuente despertar del proletariado", La Acción Socialista, 16 de mayo de 1909, p. 1.

54. La misiva que envió Villanueva a Cuomo decía lo siguiente: "En cuanto a los presos que me recomendaron se estudiará el caso de cada uno y me contestarán. La lista general recién se va a clasificar el lunes, si se normaliza el tráfico. Pueden ustedes tener la seguridad de que cumpliré lo prometido y que será puesto en libertad todo detenido que no tenga malos antecedentes o no haya cometido faltas graves o delitos", en "Reunión de delegados gremiales", La Vanguardia, 9 de mayo de 1909, p. 1. 55. "Otra vez sobre la última huelga general: los comentarios socialistas", La Acción Socialista, 1 de julio de 1909, p. 1. 
general. Sin embargo, demostraron un alto grado de pragmatismo a la hora de negociar. Este proceder cuestiona la supuesta negativa de los sindicalistas a parlamentar con el Estado.

En su primera década de existencia, la relación que estableció el sindicalismo revolucionario con el anarquismo atravesó por diferentes momentos. En la Semana Roja actuaron en consonancia, con cierta primacía de la corriente sindicalista. Sobre este vínculo tan estrecho y la subordinación del anarquismo al sindicalismo revolucionario, aquí sólo podemos arriesgar una posible explicación. La fallida huelga general de 1908, convocada por la FORA, asestó un duro golpe al movimiento libertario, llegando a mayo de 1909 con sus fuerzas disminuidas. Pero además, esos mismos hechos habrian fortalecido a sectores del anarquismo más propensos a pactar con el sindicalismo revolucionario. A su vez, el sindicalismo explotó esta situación en provecho propio. Utilizó esa alianza en función de atacar a su principal competidor en el movimiento obrero, que en aquella coyuntura histórica era el PS. Aquí no podemos más que dejar señalados estos interrogantes, su verificación exceden los límites de este trabajo.

En definitiva, los sindicalistas aparecen como la corriente más dinámica del movimiento obrero. Sus militantes ocuparon lugares destacados dentro de las organizaciones gremiales. En estos momentos avanzaban, consolidando sus posiciones, en alianza con el anarquismo y enfrentados abiertamente con el Partido Socialista. El triunfo de la huelga general lo consideraron su propia victoria, la demostración práctica de las potencialidades de la acción directa, desmintiendo el parlamentarismo de los reformistas. Al mismo tiempo, hacian gala de un gran pragmatismo. La transacción con el Estado no les era ajena. Estuvieron presentes en todos los eventos clave del movimiento obrero, en la lucha y en la mesa de negociaciones. La historia del movimiento obrero ha sido escrita sin tener en consideración a este actor fundamental, su inclusión no sólo afecta aspectos parciales, obliga a una reelaboración global de nuestra perspectiva del período.

\section{Bibliografia}

Abad de Santillán, D. (1933), La FORA: ideología y trayectoria del movimiento obrero revolucionario en la Argentina, Buenos Aires: Nervio.

- (2010), "Policía y reclutamiento: hombres y organización policial en Buenos Aires, 1880 y 1910", Horizontes y Convergencias.

Bertolo, M. (1993), Una propuesta gremial alternativa: el sindicalismo revolucionario (1904-1916), Buenos Aires: CEAL.

Bilsky, E.J. (1985), La F.O.R.A. y el movimiento obrero: 1900-1910, 2 vols., Buenos Aires: CEAL. 
Dickmann, E. (1949), Recuerdos de un militante socialista, Buenos Aires: La Vanguardia.

Falcón, R. (1987), "Izquierdas, régimen político, cuestión étnica y cuestión social en Argentina (1890-1912)", Anuario, Escuela de Historia, Universidad Nacional de Rosario, segunda época, 12, pp. 365-389.

Frydenberg, J., y M. Ruffo (1992), La Semana Roja de 1909, 2 vols., Buenos Aires: CEAL.

Godio, J. (1972), El movimiento obrero y la cuestión nacional. Argentina : inmigrantes asalariados y lucha de clases, 1880-1910, Buenos Aires: Erasmo.

Íscaro, R. (1958), Origen y desarrollo del movimiento sindical argentino, Buenos Aires: Anteo.

Lobato, M.Z. (2011), Buenos Aires: manifestaciones, fiestas y rituales en el siglo $X X$, Buenos Aires: Biblos.

Marotta, S. (1961), El movimiento sindical argentino: su génesis y desarrollo, vol. II: 1907-1920, Buenos Aires: Lacio.

Oddone, J. (1934), Historia del socialismo argentino, 2 vols., Buenos Aires: La Vanguardia.

Partido Socialista (1909), La huelga general de la semana de mayo 1909: informe de la secretaria general del Partido Socialista a las organizaciones afiliadas, Buenos Aires: La Vanguardia.

Suriano, J. (1988), Trabajadores, anarquismo y Estado represor: de la ley de residencia a la ley de defensa social (1902-1910), Buenos Aires: CEAL.

- (2001), Anarquistas: cultura y politica libertaria en Buenos Aires, 18901910, Buenos Aires: Manantial.

Titulo: The revolutionary unionism in the Red Week: the dispute for the direction of the strike

Resumen: La "semana roja" de 1909 fue uno los principales conflictos obreros de la primera década del siglo XX. El Partido Socialista elaboró una interpretación que se transformó en canónica, donde quedan relegadas las otras fuerzas políticas. En este trabajo rescatamos el rol protagónico que tuvo el sindicalismo revolucionario en estos acontecimientos.

Palabras clave: Sindicalismo revolucionario - Partido Socialista - Anarquismo - Semana Roja

Abstract: The "red week" of 1909 was one of the main labor conflicts of the first decade of the twentieth century. The Socialist Party elaborated an interpretation that became canonical, where the other political forces are relegated. In this work we rescue the leading role of revolutionary syndicalism in these events.

Keywords: Revolutionary Syndicalism - Socialist Party - Anarchism - Red Week

Recepción: 3 de enero de 2017. Aprobación: 4 de marzo de 2017. 